\title{
A produção tecnológica na odontologia: o registro
}

Technological production in Dentistry: the patent registration

CGiordani Santos Silveira ${ }^{1}$, Laíze Rosa Pires Freitas ${ }^{1}$, Fernanda Cristina Campolina e Silva²,

Humberto Torres MarquesNeto'

Dauro Douglas Oliveira ${ }^{1}$
${ }^{1}$ Programa de Pós-graduação em Odontologia, Pontifícia Universidade Católica de Minas Gerais. Belo Horizonte, MG

2 Pró-Reitoria de Pesquisa e Pós-Graduação da Pontifícia Universidade Católica de Minas Gerais. Belo Horizonte, MG

\section{$\triangle$ Giordani Silveira}

Av. Dom José Gaspar, 500/Pr. 46/Sala 101. Coração Eucarístico CEP: 30535-901

Belo Horizonte - MG

ᄀ giordanisilveira@hotmail.com

\section{RESUMO}

A geração de conhecimento obtida por meio da pesquisa científica materializa-se no anúncio dos resultados à sociedade. Este se faz basicamente de 2 formas: com apresentações em congressos e publicação de artigos científicos, ou por meio da solicitação de patentes. Se há intenção em auferir ganhos financeiros e materiais com as descobertas, ideias e inventos resultantes da pesquisa, a solicitação de uma patente se faz necessária. O objetivo deste artigo foi contribuir com a divulgação das informações pertinentes às patentes para o profissional da Odontologia brasileira. Uma descrição sucinta das etapas necessárias para a sua solicitação foi realizada. Deve-se reconhecer o esforço do Instituto Nacional de Propriedade Industrial (INPI) em disponibilizar no seu sítio eletrônico todas as informações necessárias aos interessados em fazer um pedido de patente, de maneira inteligível e didática, possibilitando a estes realizar seus próprios pedidos de patente de maneira autônoma.

Palavras-chave: patentes, inovação, odontologia

\section{ABSTRACT}

The generation of knowledge obtained through scientific research materializes in the announcement of results to society. This is basically done in two ways: with presentations at congresses and publication of scientific articles, or through the application for patents. If there is an intention to make financial and material gains with the discoveries, ideas and inventions resulting from the research, the application for a patent is necessary. The aim of this article was to contribute to the dissemination of information pertinent to patents for the Brazilian Dentistry professional. A brief description of the steps required for its request has been made. It must be recognized the effort of the Instituto Nacional da Propriedade Industrial (INPI) to make available on its website all the information necessary to those interested in making a patent application, in an intelligible and didactic way, enabling them to make their own patent applications.

Keywords: patent, innovation, dentistry 


\section{INTRODUÇÃO}

A geração de conhecimento obtida por meio da pesquisa científica, seja ela acadêmica, básica ou aplicada, materializa-se no anúncio dos resultados à sociedade. Este se faz basicamente de 2 formas: com apresentações em congressos e publicação de artigos científicos, ou por meio da solicitação de patentes. A escolha de qual modalidade de divulgação do conhecimento depende dos objetivos a serem atendidos (CONSOLARO, 2007; PONTIFÍCIA UNIVERSIDADE CATÓLICA DE MINAS GERAIS, 2008).

Quando os pesquisadores desejam disponibilizar suas observações, ideias, invenções ou modificações de técnica sem um interesse financeiro subjacente, deve-se optar pela publicação de artigos científicos em periódicos ou apresentação em reuniões e congressos. Desta forma, o conhecimento torna-se de domínio público, permitindo a sua aplicação imediata ou fomentando outros pesquisadores a testá-lo, aperfeiçoálo ou até mesmo utilizá-lo como base para novas linhas de pesquisa. A recompensa para os pesquisadores é a possibilidade de aumento do prestígio intelectual e da valorização profissional na comunidade científica através das citações bibliográficas (CONSOLARO, 2007; PONTIFÍCIA UNIVERSIDADE CATÓLICA DE MINAS GERAIS, 2008).

Se há intenção em obter ganhos financeiros e materiais com as descobertas, ideias e inventos resultantes da pesquisa, a solicitação de uma patente se faz necessária. A patente é um título de propriedade temporário, oficial, concedido pelo Estado, por força de lei, ao seu titular ou seus sucessores (pessoa física ou jurídica), que passam a possuir os direitos exclusivos sobre o bem, seja de um produto, de um processo de fabricação ou do aperfeiçoamento de produtos e processos já existentes (CARVAJAL et al., 2017; INSTITUTO NACIONAL DA PROPRIEDADE INDUSTRIAL, 2015; PONTIFÍCIA UNIVERSIDADE CATÓLICA DE MINAS GERAIS, 2008). Em outras palavras, é uma espécie de contrato entre o inventor e a sociedade, em que o primeiro se compromete a tornar público a descrição detalhada do seu invento, recebendo em troca o direito exclusivo de explorá-lo comercialmente durante um certo período. A sociedade beneficia-se com esta divulgação pública do invento que, de outra forma, permaneceria em sigilo (TEIXEIRA, 2006).

$\mathrm{Na}$ Odontologia e, mais especificamente na Ortodontia, há muitas técnicas, dispositivos e abordagens, que aumentam a possibilidade de desenvolvimento de instrumentos novos ou modificados, dispositivos e formas de tratamento (CONSOLARO, 2007). A despeito desta particularidade, surpreendentemente, a disponibilidade de informações nos periódicos odontológicos brasileiros sobre patentes é quase inexistente. Da mesma forma, a grade curricular dos cursos de Odontologia e dos demais cursos da área de saúde não possui disciplinas sobre "Registro de Patentes" ou "Propriedade Industrial" (CARVAJAL et al $., 2017)$.

Desta forma, o objetivo deste artigo foi contribuir com a divulgação das informações pertinentes às patentes para o profissional da Odontologia brasileira, no intuito de preencher esta lacuna, bem como descrever de forma sucinta as etapas necessárias para a sua solicitação.

\section{REVISÃO DA LITERATURA}

\section{Patente: Definições e características}

Todas as criações que impliquem em desenvolvimento que acarrete em solução de um problema ou avanço tecnológico em relação ao que já existe e que possuam aplicação industrial são, a princípio, passíveis de proteção intelectual (INSTITUTO NACIONAL DA PROPRIEDADE INDUSTRIAL, 2015).

A concessão da patente pelo Estado é a recompensa ao titular pelos esforços e gastos despendidos na sua criação. Portanto, é um instrumento de incentivo à contínua renovação tecnológica, estimulando o investimento das empresas, universidades e institutos de pesquisa para o desenvolvimento de novas tecnologias e produtos para a sociedade (INSTITUTO NACIONAL DA PROPRIEDADE INDUSTRIAL, 2015).

Um importante aspecto do direito de uso exclusivo da patente pelo seu titular é a validade limitada a um determinado período de tempo. A vigência para patente de invenção é de 20 anos e para modelo de utilidade, de 15 anos, contados a partir da data do depósito do pedido. Após este período, a patente cai em domínio público, estando disponível para ser usada por toda a sociedade, incentivando não só o inventor a prosseguir na pesquisa de aperfeiçoamentos, mas também os seus concorrentes (INSTITUTO NACIONAL DA PROPRIEDADE INDUSTRIAL， 2015; PONTIFÍCIA UNIVERSIDADE CATÓLICA DE MINAS GERAIS, 2008).

$A$ validade territorial de uma patente restringe-se aos países onde ela foi requerida e que concederam a sua proteção. Cada país é soberano para concedêla ou não, independentemente da decisão em outros países sobre pedidos de patentes depositados nos mesmos (INSTITUTO NACIONAL DA PROPRIEDADE INDUSTRIAL, 2015).

De acordo com o Art. 2o, inciso I da Lei da Propriedade Industrial (LPI), a concessão de patente pode ser de 2 tipos: de invenção ou de modelo de utilidade. A de invenção é definida como sendo um produto ou uma atividade industrial inédita que represente uma solução nova para um problema técnico existente e que possa ser fabricado. De acordo com 
o Art. 80 da LPI, para ser patenteável, uma invenção deve atender simultaneamente a 3 requisitos básicos: novidade, atividade inventiva e aplicação industrial. $O$ modelo de utilidade é a criação referente a um objeto de uso prático, ou parte deste, que apresente nova forma ou disposição, que resulte em melhoria funcional no seu uso ou em sua fabricação. Deve envolver também ato inventivo e ter aplicação industrial para ser patenteável. (Art. 9o da LPI) (INSTITUTO NACIONAL DA PROPRIEDADE INDUSTRIAL, 2015).

Submissão da patente no Instituto Nacional da Propriedade Industrial (INPI)

\section{Busca prévia}

Apesar de não ser obrigatória, recomenda-se a realização de busca nos bancos de dados antes do requerimento do pedido de registro para verificar se já existe algo igual ou semelhante àquilo que se quer patentear, já que o ineditismo é requisito para a obtenção da carta-patente. A busca também é uma importante ferramenta de pesquisa e monitoramento, disponível gratuitamente para todos os interessados no sítio eletrônico do Instituto Nacional da Propriedade Industrial - INPI (http://www.inpi.gov.br).

Há um guia prático para realização de buscas de patentes, inclusive em 4 bases de dados. Base do INPI: acesso a pedidos de patente depositados no Brasil; Base Latipat: patentes depositadas na Espanha e em países da América Latina; Base Espacenet: patentes de mais de 90 países (base de maior abrangência); e Base Patentscope: patentes de mais de 40 países.

\section{Depósito do pedido de patente}

Após a confirmação da originalidade na busca prévia, deve-se realizar o cadastramento no e-INPI e providenciar os seguintes documentos:

1) Requerimento: formulário de "Depósito do Pedido de Patente", disponível no Passo 4 do Guia básico de patente no sítio eletrônico do INPI;

2) relatório descritivo: claro e preciso sobre o objeto do pedido;

3) quadro reivindicatório: estabelece os direitos do inventor/criador, definindo a matéria para a qual a proteção é solicitada. Deve conter os aspectos técnicos relacionados à invenção ou modelo;

4) desenhos (se for o caso): auxiliam na compreensão do objeto a ser protegido;

5) resumo;

6) comprovante de pagamento da Guia de Recolhimento da União relativa ao depósito (artigo 19 da LPI).

No que diz respeito ao conteúdo técnico (itens: 2 ,
3, 4 e 5), o Manual para o Depositante de Patentes também no Passo 4 do Guia básico de patente, disponível no sítio eletrônico do INPI, apresenta os detalhamentos relativos à redação, principalmente, do Relatório Descritivo e Reivindicações.

Está disponível o depósito eletrônico do pedido de patente através do e-patentes no sítio eletrônico do INPI. Se preferir, o pedido também continua sendo depositado presencialmente, em papel, na Sede do INPI no rua Mayrink Veiga, 9 - Centro, Rio de Janeiro/RJ ou em uma representação do INPI nas outras capitais do Brasil. Há ainda a possibilidade de depósito por via postal.

\section{Acompanhamento}

Os pedidos de patentes são publicados semanalmente na Revista de Propriedade Industrial (RPI), disponível gratuitamente no portal do INPI. O acompanhamento da tramitação do Pedido de Patente é de inteira responsabilidade do usuário, sob o risco de possível arquivamento definitivo, caso não atenda às exigências publicadas na RPI.

Após o depósito do pedido, é publicado na RPI o despacho referente à notificação de requerimento de pedido de patente. O pedido é enviado para o Setor de Exame Formal. Caso não atenda ao disposto no artigo 19 da LPI e/ou às demais disposições quanto à sua forma, de acordo com as Instruções Normativas nos 30 e $31 / 2013$, é publicado um despacho para cumprimento de exigências formais, que devem ser atendidas em 30 dias; se este prazo expirar, o pedido é anulado. Se o pedido estiver atendendo todas as exigências formais citadas anteriormente, é publicado o despacho notificando o Pedido de Patente protocolizado. Este pedido fica mantido em sigilo por 18 meses a partir da data do depósito.

Após o período de sigilo, é publicada n RPI o despacho relativo à notificação da publicação do conteúdo técnico Pedido de Patente. Feito isso, um examinador de Patentes analisa o pedido e dá um parecer sobre a aceitação (deferimento) ou rejeição (indeferimento). Exigências para reformulação do pedido podem ser solicitadas pelo examinador antes da decisão final. 0 prazo de resposta é de 90 (noventa) dias da publicação na RPI; caso seja desrespeitado, o pedido pode ser arquivado definitivamente, inviabilizando a proteção patentária. Uma vez atendidas todas as exigências, a Carta-Patente é emitida em formato eletrônico (FIGURA 1).

\section{Obrigações do depositante de patente}

a) pedido de Exame Técnico (Resolução $P R$ no 94/2013): deve ser requerido com data limite até o 360 mês, a partir da data do depósito; 


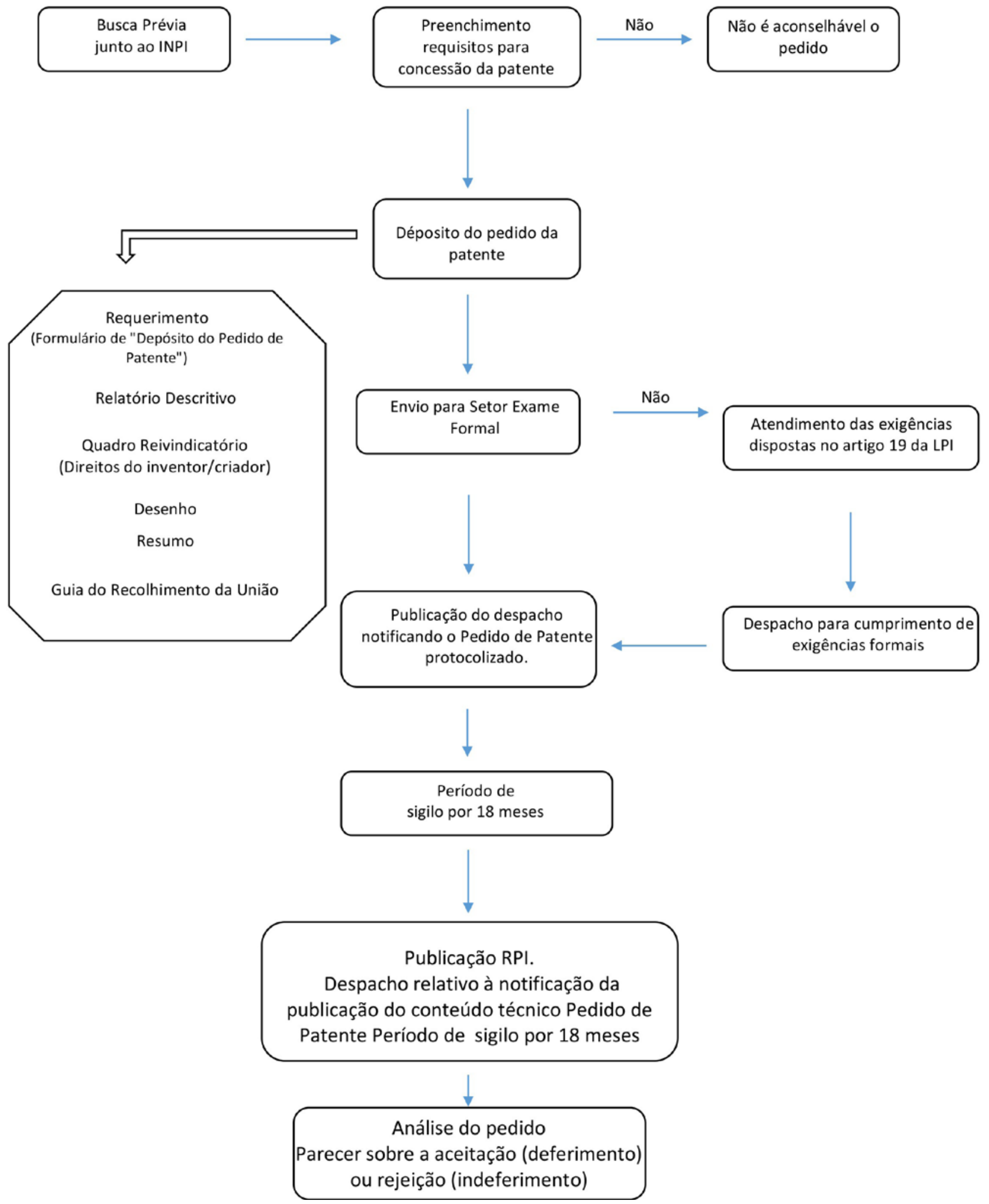

Figura 1: Fluxograma dos passos para registro do pedido de patente junto ao INPI 
b) pagamento das anuidades (Resolução PR no 113/2013): deve ser efetuado a partir do 20 aniversário a partir da data do depósito. Enquanto a patente não for concedida, o valor será referente à anuidade de pedido de patente (valor fixo e reduzido). Após a concessão da carta-patente, o valor será referente à anuidade de patente (valores variáveis, aumentando conforme a idade da patente);

c) cumprimento das exigências formais (30 dias) e técnicas (60 dias) a partir da publicação na RPI;

d) pagamento da Expedição da Carta-Patente no prazo de 60 dias (prazo ordinário) a partir da publicação do deferimento na RPI.

\section{DISCUSSÃO}

O empreendedorismo de uma nação pode ser avaliado através da sua capacidade de inovar e desenvolver novos produtos e serviços. Muitas vezes o desenvolvimento destas tecnologias gera divisas, as quais fomentam o desenvolvimento econômico e social do país (FABER, 2010). Além disso, os países que mais produzem ciência e tecnologia são aqueles que mais impulsionam seus processos globalmente (TARGINO, 2000).

O desenvolvimento de tecnologia de um país é medido pelo número de depósitos de patentes realizados. Infelizmente, no Brasil, o número de depósitos de patentes é incipiente quando comparado ao de países desenvolvidos (FABER, 2010). Especificamente na Odontologia, o número de registros de patentes apresentou um decréscimo acentuado nos últimos anos, de 358 registros em 2004 para apenas 14 registros em 2016 (SILVA, 2018). Por outro lado, a produção científica brasileira tem um local de destaque no contexto mundial. Isto revela uma aparente cisão entre a produção de ciência e a de tecnologia no Brasil, inclusive com raízes históricas (FABER, 2010). O diálogo entre o conhecimento científico e a inovação tecnológica precisa ser priorizado urgentemente, e o Estado brasileiro deve fornecer amparo legal, iniciativas e políticas educacional e industrial para este fim.

A Lei da Propriedade Industrial, Lei no. 9279 de 1996, regula os direitos e as obrigações relativas à propriedade industrial por meio da concessão de patentes, marcas, desenhos industriais e localizações geográficas, além de evitar a concorrência desleal (BRASIL, 1996). Posteriormente, duas leis foram promulgadas com objetivo de complementá-la e de estimular a geração de patentes, inclusive em universidades. São elas: a Lei da Inovação, Lei no 10.973 de 2004, que "visa estimular a interação das universidades com o setor produtivo, sendo que para isso as universidades precisam se adequar às novas exigências que incluem, entre outras ações, a criação de Núcleos de Inovação Tecnológica" (BRASIL, 2004); e a chamada Lei do Bem, Lei no 11.196 de 2005, que concede benefícios às empresas que investem em inovação (BRASIL, 2005).

Deve-se reconhecer o esforço do INPI, uma autarquia federal, em disponibilizar no seu sítio eletrônico todas as informações necessárias aos interessados em fazer um pedido de patente, de maneira inteligível e didática. Não menos importante é a possibilidade de realizar todos os passos de maneira eletrônica, o que agiliza o processo e reduz os custos envolvidos. Os valores atualizados das taxas cobradas pelo INPI estão disponíveis no endereço: (http://www.inpi.gov.br/menu-servicos/ patente/arquivos/tabela-de-retribuicao-de-servicos-depatentes-inpi-20170606.pdf).

Outra iniciativa do Estado favorável ao incremento da inovação tecnológica foi a Portaria normativa no. 17, de 2009, que permitiu a apresentação do trabalho de conclusão de curso (TCC) do mestrado profissional na forma de patentes, registros de propriedade intelectual, projetos técnicos, dentre outros (MEC, 2009). Neste contexto, no âmbito da pós-graduação stricto sensu, das modalidades de mestrado e doutorado profissional (MEC, 2017), espera-se também a geração e aplicação de processos de inovação.

Entretanto, avanços são necessários, pois o sistema brasileiro de patentes não está isento de críticas, especialmente em relação ao excesso de burocracia e à demora entre depósito e concessão, assim como o sistema judiciário, pela sua lentidão em relação ao sistema de patentes (MUELLER; PERUCCHI, 2014).

\section{CONCLUSÃO}

Pelo exposto no artigo, não há empecilho para o profissional da Odontologia realizar seu próprio pedido de patente de maneira autônoma. Mas se não se sentir completamente seguro em fazê-lo e tiver orçamento favorável, pode contratar um escritório de advocacia especializado em patentes para assessorá-lo.

Vale ainda ressaltar que o depósito do pedido de patente não impede a sua posterior publicação em artigos científicos ou divulgação em congressos. Já a publicação prévia ao depósito de patente pode inviabilizar a concessão da patente uma vez que o requisito de novidade fica comprometido.

\section{FINANCIAMENTO}

O presente trabalho foi realizado com apoio da Coordenação de Aperfeiçoamento de Pessoal de Nível Superior - Brasil (CAPES) - Código de Financiamento 001.

\section{REFERÊNCIAS}

BRASIL. Lei no 9.279, de 14 de maio de 1996. Regula direitos e obrigações relativos à propriedade industrial. Diário Oficial da União, Brasília, DF, 14 maio 1996. Seção 1, p. 8353. 
BRASIL. Lei no 10.973, de 2 de dezembro de 2004. Dispõe sobre incentivos à inovação e à pesquisa científica e tecnológica no ambiente produtivo e dá outras providências. Diário Oficial da União, Brasília, DF, 2 dez. 2004. Seção 1, p. 2.

BRASIL. Lei 11.196, de 21 de novembro de 2005. Dispõe sobre incentivos fiscais para a inovação tecnológica e dá outras providências. Diário Oficial da União, Brasília, DF, 21 nov. 2005. Seção e, p. 1.

CARVAJAL, P.C.C. et al. Manual para registro de patentes para profissionais da saúde. South American Development Society Journal, v.3, n.8, p. 83-107, aug. 2017.

CONSOLARO, A. Sobre ineditismo de ideias, citações de autores, marcas comerciais e patentes na Ortodontia. Revista Dental Press de Ortodontia e Ortopedia Facial, v.12, n.2, p. 11-13, apr. 2007.

FABER, J. Innovations needs to be stimulated in Brazil by means of patent applications. Dental Press Journal of Orthodontics, v.15, n.4, p. 5, jul./aug. 2010.

INSTITUTO NACIONAL DA PROPRIEDADE INDUSTRIAL. Manual para o depositante de patentes. Brasília: INPI, 2015. $50 \mathrm{p}$.

MEC. Portaria Normativa 17, de 28 de dezembro de 2009. Diário Oficial da União, no. 248, 29 de dezembro de 2009. Disponível em: https://www.capes.gov.br/images/stories/ download/legislacao/PortariaNormativa_17MP pdf. Acesso em: 15 dez. 2018.

MEC. Portaria Normativa 389, de 23 de março de 2017. Diário Oficial da União, no. 58, 23 de março de 2017. Disponível em: http://www.capes.gov.br/images/stories/download/ legislacao/24032017-PORTARIA-No-389-DE-23-DE-MARCODE-2017.pdf. Acesso em: 15 dez. 2018.

MUELLER, S.P.M.; PERUCCHI V. Universidades e a produção de patentes: tópicos de interesse para o estudioso da informação tecnológica. Perspectivas em Ciências da Informação, v.19, n.2, p.15-36, abr. 2014.

PONTIFÍCIA UNIVERSIDADE CATÓLICA DE MINAS GERAIS. Cartilha de proteção do conhecimento da Pró-reitoria de Pesquisa e Pós-graduação. Belo Horizonte: PUC Minas, 2008. 21p.

SILVA, L.M. Patentes odontológicas depositadas no Brasil indexadas na Base Derwent Innovations Index (DII) no período de 2014-2016. 2018. 67f. Trabalho de Conclusão de Curso (Graduação em Biblioteconomia) - Faculdade de Biblioteconomia, e Comunicação, Universidade Federal do Rio Grande do Sul, Porto Alegre, 2018.

TARGINO, M. G. Comunicação científica: uma revisão de seus elementos básicos. Informação \& Sociedade: Estudos, v. 10, n. 2, p. 1-27, 2000.
TEIXEIRA, F. Tudo o que você queria saber sobre patentes mas tinha vergonha de perguntar. São Paulo: Interfarma, 2006. 147p. 